\title{
Method Validation for Analysis of Aroclor 1260 in Transformer Oil using Gas Chromatography - Electron Capture Detection
}

\author{
J.J. Jeevanantham ${ }^{1}$, D.A.T.W.K. Dissanayake ${ }^{2 *}$, G.V.V. Liyanaarachchi², M.N.A. Mubarak ${ }^{2}$, W.M.A.K. \\ Wijesinghe $^{2}$ and J. K. A. B. Wijegunasekara ${ }^{2}$ \\ ${ }^{1}$ College of Chemical Sciences, Institute of Chemistry Ceylon, Adamantane House, 341/22 Kotte Road, \\ Welikada, Rajagiriya, Sri Lanka \\ ${ }^{2}$ Industrial Technology Institute, 363, Bauddhaloka Mawatha, Colombo7, Sri Lanka.
}

Date Received: 06-12-2018

Date Accepted: 20-12-2019

\begin{abstract}
Since early 1980's, the production and usage of Polychlorinated biphenyls (PCBs) have been banned throughout the world due to its carcinogenicity to humans and animals. However, due to the large halflives of PCBs, large amounts of stocks are still available in storage. This study presents the validation data of the method developed for analysis of Aroclor 1260 in transformer oils in order to determine the concentrations for systematic disposal and destruction.

The transformer oil samples were prepared according to the ASTM D 4059 with few modifications. PCBs in transformer oils were extracted with iso-octane followed by deactivated florisil cleanup and detection by GC - ECD using HP 5 GC column $(30 \mathrm{~m}$ x $0.32 \mathrm{~mm}$ x $0.25 \mu \mathrm{m})$. The study was performed under matrix matched condition to eliminate the matrix effect that was found to be significant. The method was found linear over a wide working range from $2.5 \mathrm{ppm}-100 \mathrm{ppm}$ with a regression coefficient of 0.994 and a lower limit of determination of $2.5 \mathrm{ppm}$. Method showed satisfactory repeatability with relative standard deviation below $7 \%$ over the entire working range. Accuracy of the method was assured using spike recoveries at $5 \mathrm{ppm}, 10 \mathrm{ppm}$ and $50 \mathrm{ppm}$ with 85\%,105\% and 93\% respectively. The selectivity of Aroclor 1260 was confirmed against Aroclor 1254 and Aroclor 1242 considering uniquely identified non - overlapping chromatographic peaks.

Based on the performance characteristics, this method can be suggested as an accurate and precise methodology to analyze Aroclor 1260 present in transformer oil.
\end{abstract}

Keywords: PCB, Transformer oil, Aroclor 1260, Gas Chromatography, Electron capture detector.

\section{Introduction}

PCB is expanded as Poly Chlorinated Biphenyl. PCBs are a group of synthetic organic chemicals consisting of carbon, hydrogen and chlorine atoms. The number of chlorine atoms and their location in a PCB molecule determine many of its physical and chemical properties. PCBs are also categorized as a constituent member of poly aromatic hydrocarbons (Schantz, 1996). PCBs have no known taste or smell, and range in consistency from an oil to a waxy solid.The Solubility of certain congeners of PCB is as low as $0.0013 \mathrm{ug} / \mathrm{ml}($ Lang, 1992)

The chemical properties primarily responsible for many of the industrial applications of PCBs that is, their inflammability, chemical stability, and miscibility with organic compounds (i.e., lipophilicity), accounts for their use as thermal insulators and coolants mainly in transformers, capacitors, electrical equipment including voltage regulators, switches, re-closers, bushings, electromagnets, oils used in motors and hydraulic systems.

*Correspondence:thanuja@iti.lk

Tel: +94112379978

ISSN 2235-9370 Print/ISSN 2235-9362 Online @2017 University of Sri Jayewardenepura 
PCBs were also used in fluorescent light ballasts, cable insulation, adhesives, tapes, oil-based paints, caulking, plastics, carbonless copy paper and floor finish (Safe, 1994; Bowman et al., 2010)(Erickson and Kaley, 2011).

Despite their wide use in industry, PCBs have been classified as a type 1 Carcinogen by the International agency for research on cancer (IARC) (International Agency for Research on Cancer, 2018). Earlier, PCBs were classified as a 2B carcinogen due to the studies showing that rats developed tumors in the liver after a prolong exposure to PCBs (Kamohara, Yagi and Itokawa, 1984; Safe, 1985). However, in late 70s, there were a few accidental poisonings leading to enhanced concern on studies related to toxicity of PCBs (Grittini et al., 1995). PCBs are absorbed through ingestion, inhalation, and dermal exposure, after which they are transported similarly through the circulation (Schantz, 1996). Sensitized individuals may develop a rash after 2 days of exposure by contact or inhalation (Andric et al., 2006), and also have shown through studies that PCBs can interfere with endocrine hormones by mimicking and biding with the active site(Chris, 1991). Studies also have shown that PCB acts as an embryo toxic and teratogen to birds (Hoffman et al., 1996) Furthermore PCBs have also effected in birds since the second world war by the pattern of calcium metabolism. According to studies PCBs have made eggshells of birds thinner(Lohmann and Dachs, 2019). Furthermore because of their persistence in the environment, the bioaccumulation in human and animal tissues (Kamohara, Yagi and Itokawa, 1984), PCBs have also been detected in human breast milk and they have a large potential to have chronic or delayed toxicity (Schantz, 1996). Due to the risk of carcinogenicity, the general disposal methods are cannot be considered safe since PCBs have long half-lives (Seegal et al., 2011). Therefore, disposal of PCBs are carried out using specific disposal methods such as by reacting with metallic Sodium and Sulphate radicals can be used to break down PCB congeners(Fang et al., 2012), burning of PCB in cement kilns, chemical reduction, and molten metal pyrolysis (Grittini et al., 1995) etc. But in all these methods, formation of polychlorinated dioxins and furans are possible. Therefore, attention must be given to minimize the formation of hazardous byproducts. Furthermore studies have also been carried out on whether microorganisms could break down the PCB found in soil, by growing microorganisms in soil slurry(Correa et al., 2010).

In the year 2001, representatives from different countries established the Stockholm Convention to discuss issues and concerns regarding protection of the environment. According to this convention, 12 organic pollutants were identified as persistent organic pollutants (POPs) (Table 1) and Polychlorinated Biphenyl in one out of the twelve chemicals which were identified as (Stockholm Convention, 2001; ONU, 2009). The signed agreement states that all parties must work towards either destruction or disposal of stocks of PCBs by the year 2025 (ONU, 2009).

Table 1: Dirty dozen of the Stockholm convention(ONU, 2009)

\begin{tabular}{ll}
\hline Chemical & Use \\
\hline Aldrin & Pesticide (insecticide) \\
Chlordane & Pesticide (insecticide, termiticide) \\
Dieldrin & Pesticide (insecticide) \\
DDT & Pesticide (insecticide) \\
Endrin & Pesticide (insecticide, Rodenticide) \\
Heptachlor & Pesticide (insecticide, termiticide) \\
Mirex & Pesticide (insecticide, termiticide) \\
Toxaphene & Pesticide (insecticide) \\
Hexachlorobenzene & Pesticide (fungicide), by-product of solvent \\
& manufacture \\
Polychlorinated biphenyl & Industrial \\
Dioxin & By-product \\
Furan & By-product \\
\hline
\end{tabular}


Since 1929 PCBs were used in transformer oils throughout the world. In the same manner PCBs were used in transformers oils in Sri Lanka(Implementation et al., 2004)(Justice and Lanka, 2006). In 1979, PCBs were banned and ever since PCB was not added to transformer oils in Sri Lanka. In the year 2002 Sri Lanka signed the Stockholm convention on Persistent Organic Pollutants (POP)(Stockholm Convention, 2001).

Several methods in literature describe about analysis of Aroclors in transformer oil. Many authors have used expensive solid phase extraction (SPE) (Na et al., 2008; Gordon, Szlta and Feeder, 1982,) or lengthy analytical procedures (Shin et al., 2006) for Aroclor analysis. Sri Lanka, as a signatory to the Stockholm convention, it was a timely requirement in the country for the establishment of a simple, relatively cost effective and rapid method developed for analysis of Aroclor 1260, which was the most frequently detected Aroclor present in the transformers as per the preliminary assessments carried out in the country. In this relation, a simple, cost effective and a rapid method was validated for the analysis of Aroclor 1260 in transformers oils.

\section{Methodology}

\subsection{Materials and reagents}

The standard of Aroclor 1260, 500 ppm in transformer oil was purchased from Sigma Aldrich Germany. 2,2,4-Trimethylpentane/ Isooctane with a purity of $\geq 99.5 \%$ GC grade (Sigma Aldrich Germany),Deactivated magnesium silicate (Fisher Scientific - USA), The Helium and Nitrogen gasses used for the analysis were of high purity of $99.999 \%$.

\subsection{Instrumentation}

Agilent 6890 series Gas Chromatograph coupled to electron capture detector with a HP-5(5\% phenyl methyl $30 \mathrm{~m} \times 0.32 \mathrm{~mm} \times 0.25 \mu \mathrm{m}$ ) column was used for the analysis. Inlet temperature was maintained at $250{ }^{\circ} \mathrm{C}$ in split-less mode. The Aroclors were separated using a temperature programme stated at $100{ }^{\circ} \mathrm{C}$ and ended at $300{ }^{\circ} \mathrm{C}$ at a rate of $15{ }^{\circ} \mathrm{C} / \mathrm{min}$ with a flow rate of $2 \mathrm{~mL} / \mathrm{min}$. The Detector was maintained at $308^{\circ} \mathrm{C}$.

\subsection{Preparation of working standards series}

The working standards were prepared by diluting the 500 ppm Aroclor 1260 to 2.5 ppm, 7.5 ppm, 25 ppm and $100 \mathrm{ppm}$ concentrations in non-contaminated transformer oil. Then $0.10 \pm 0.01 \mathrm{~g}$ from the prepared each working standards were extracted to $10 \mathrm{~mL}$ of 2,2,4-Trimethylpentane according to the procedure explained in 2.4 to maintain the recommended dilution ratio of 50:1 of solvent: transformer oil.

\subsection{Preparation of samples}

$0.10 \pm 0.01 \mathrm{~g}$ of transformer oil sample was weighed in to a $10 \mathrm{~mL}$ glass disposable vial and diluted 50 times with $10 \mathrm{~mL}$ of 2,2,4-Trimethylpentane to obtain a 50:1 solvent ratio. Then approximately $1 \mathrm{~g}$ of deactivated magnesium silicate (Florisil) was added and vortexed for 3 mins at $2500 \mathrm{rpm}$. The supernatant was filtered using a Nylon $0.45 \mu \mathrm{m}$ syringe filter in to a $2 \mathrm{~mL}$ auto sampler vial for injection into the GCECD.

\subsection{Reagent Blanks}

If the reagent blank produces same set of peaks within \pm 0.05 min of the retention time as of the Aroclor 1260 with identical ratios observed for Aroclor 1260, the source of contamination or the interference was eliminated before processing samples.

\subsection{Fortified samples}

PCB free transformer oil was spiked with Aroclor 1260 to concentrations of $5 \mathrm{ppm}, 10 \mathrm{ppm}$, and $50 \mathrm{ppm}$ respectively. The same method was followed for the fortified sample in order to measure accuracy, precision and the recovery of the method. The fortified samples were replicated six times to evaluate the method performance characteristics. 


\subsection{Method validation}

Method performance characteristics: accuracy, precision, recovery, limit of determination (LOD), limit of quantification (LOQ) selectivity, linearity, working range were evaluated as per EURACHEM guidelines.(Eurachem, 2014)

\section{Results}

The summary of validation data is given in Table 2 .

Table 2: Results and parameters

\begin{tabular}{cccccccccc}
\hline & Recovery $\%$ & & \multicolumn{2}{c}{ Precision (\%RSD) } & $\begin{array}{c}\text { LOD } \\
(\mathrm{ppm})\end{array}$ & $\begin{array}{c}\text { LOQ } \\
(\mathrm{ppm})\end{array}$ & Linearity & $\begin{array}{c}\text { Working range } \\
(\mathrm{ppm})\end{array}$ \\
\cline { 1 - 6 } Low & Mid & High & Low & Mid & high & & \\
\hline $85 \pm 4$ & $109 \pm 6$ & $94 \pm 2$ & 5.1 & 6.7 & 2.4 & 2.5 & 5 & 0.994 & $2.5-100$ \\
\hline
\end{tabular}

\subsection{Selectivity}

Since there are 209 PCB congeners there are a large no of peaks in the chromatogram as depicted in Figure 1. This makes the identification and quantification more challenging. GC-Electron Capture Detector was used for detection. The concentration of PCB was identified by selecting the specific peaks which are unique for Aroclor 1260 as denoted in figure 1. The peaks were selected by screening Aroclor 1260 against Aroclor 1242 and Aroclor 1254 standards as given in figure 2. and figure 3.

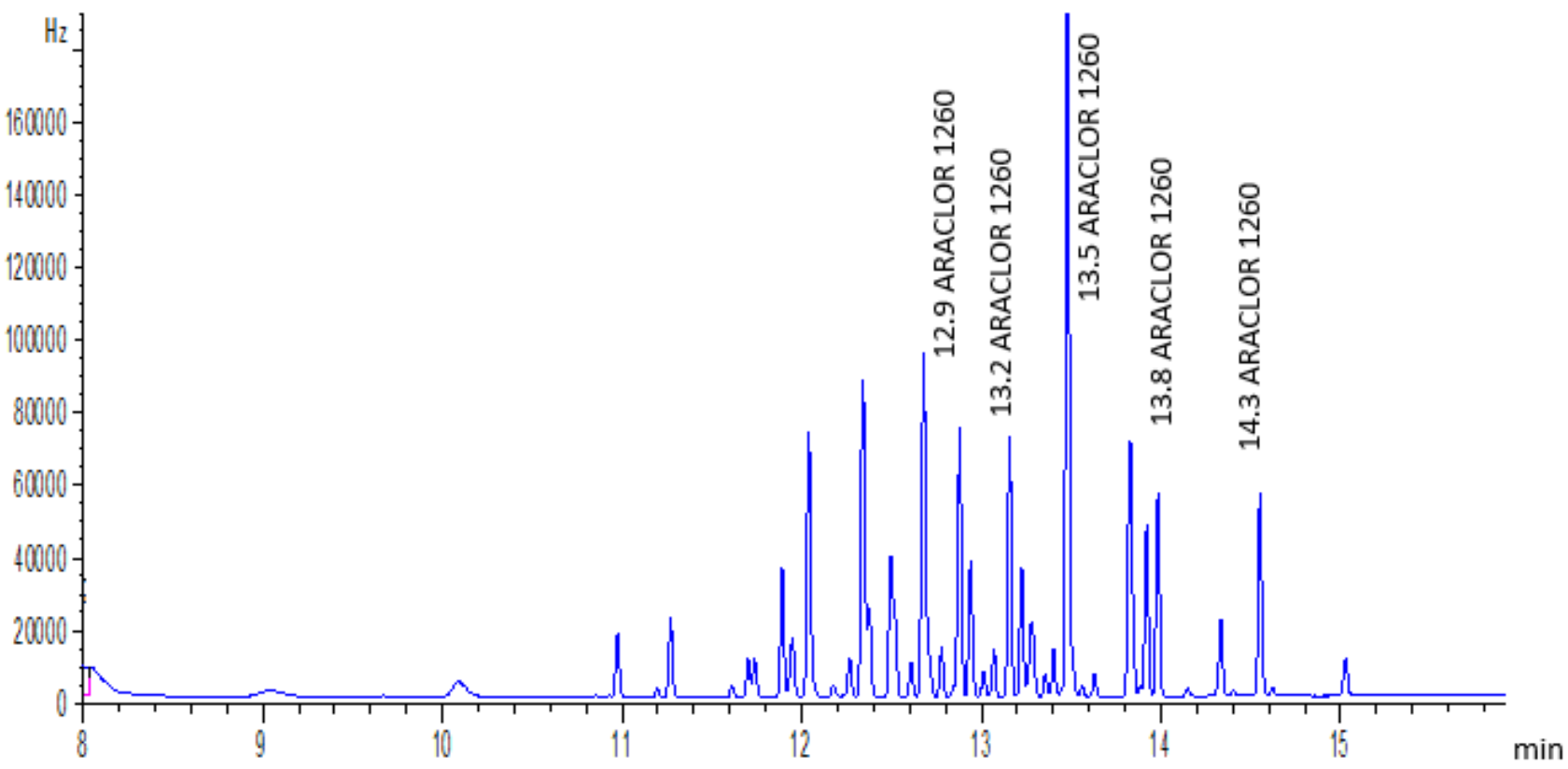

Figure 1: GC Chromatogram of Aroclor 1260 

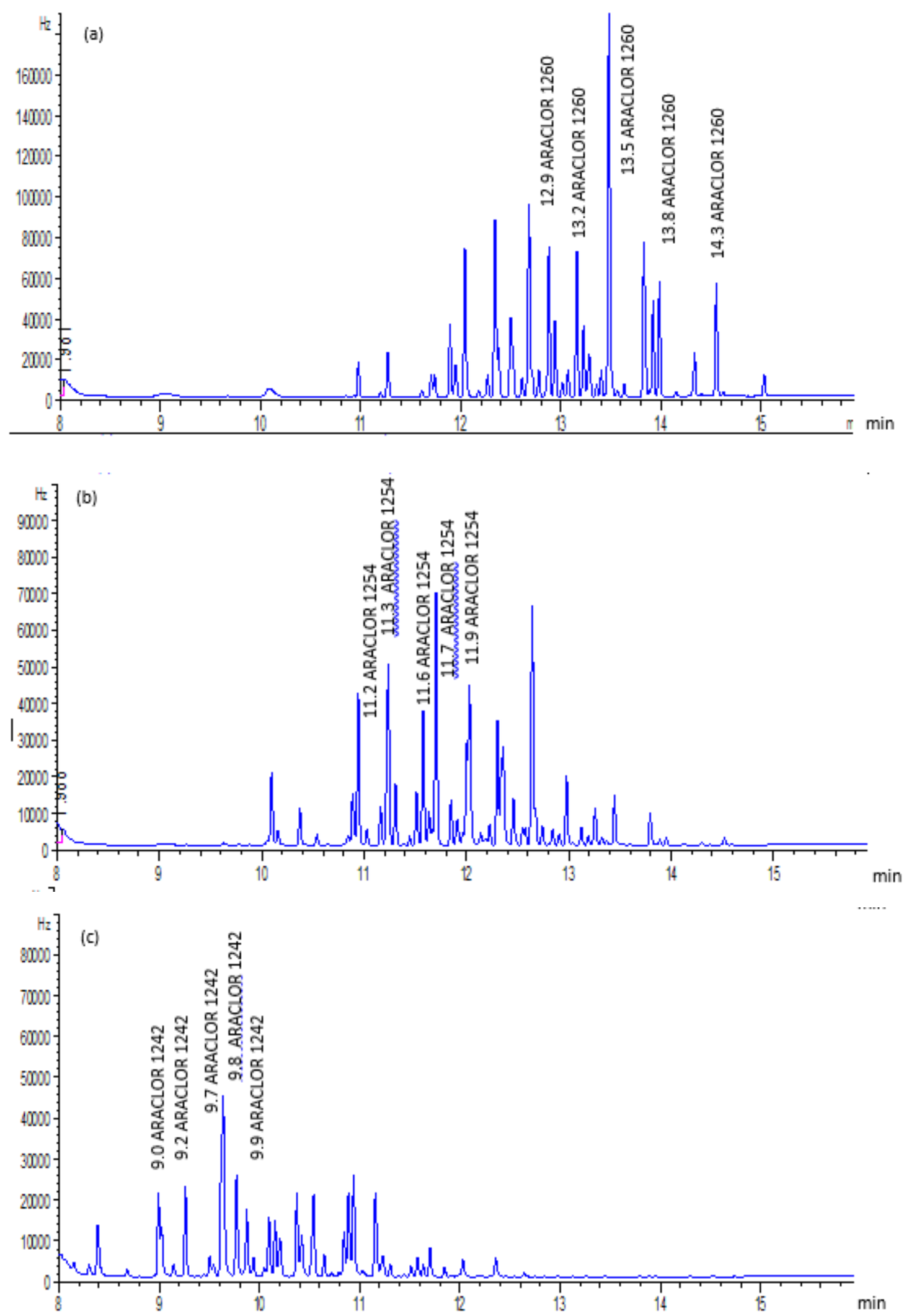

Figure 2: GC chromatograms of (a) Aroclor 1260 (b) Aroclor 1254 and (c) Aroclor 1242 
Jeevanantham et al. /Journal of Tropical Forestry and Environment Vol. 9, No. 02 (2019), 120-131
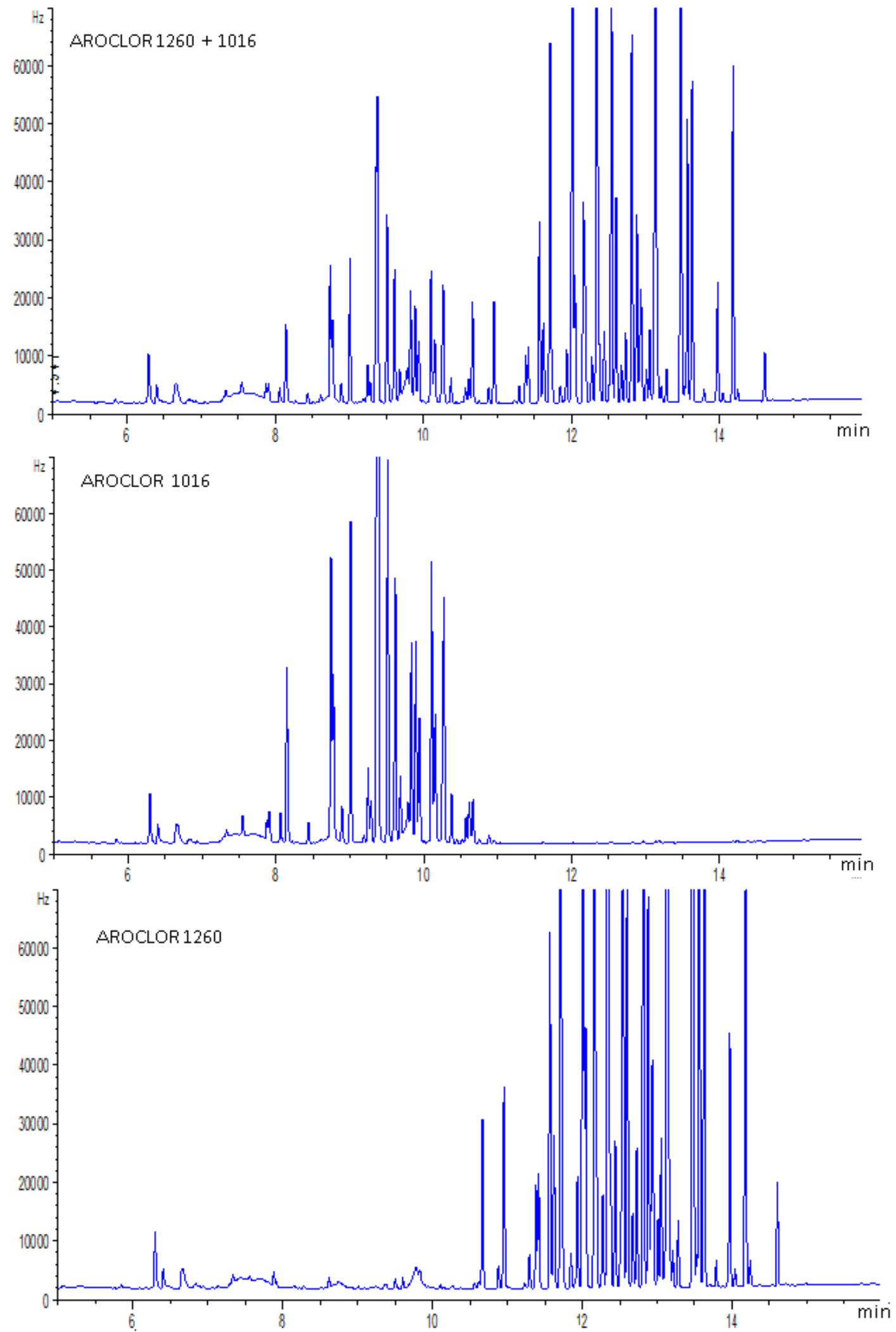

Figure 3: GC chromatograms of Aroclor 1016 and 1260 

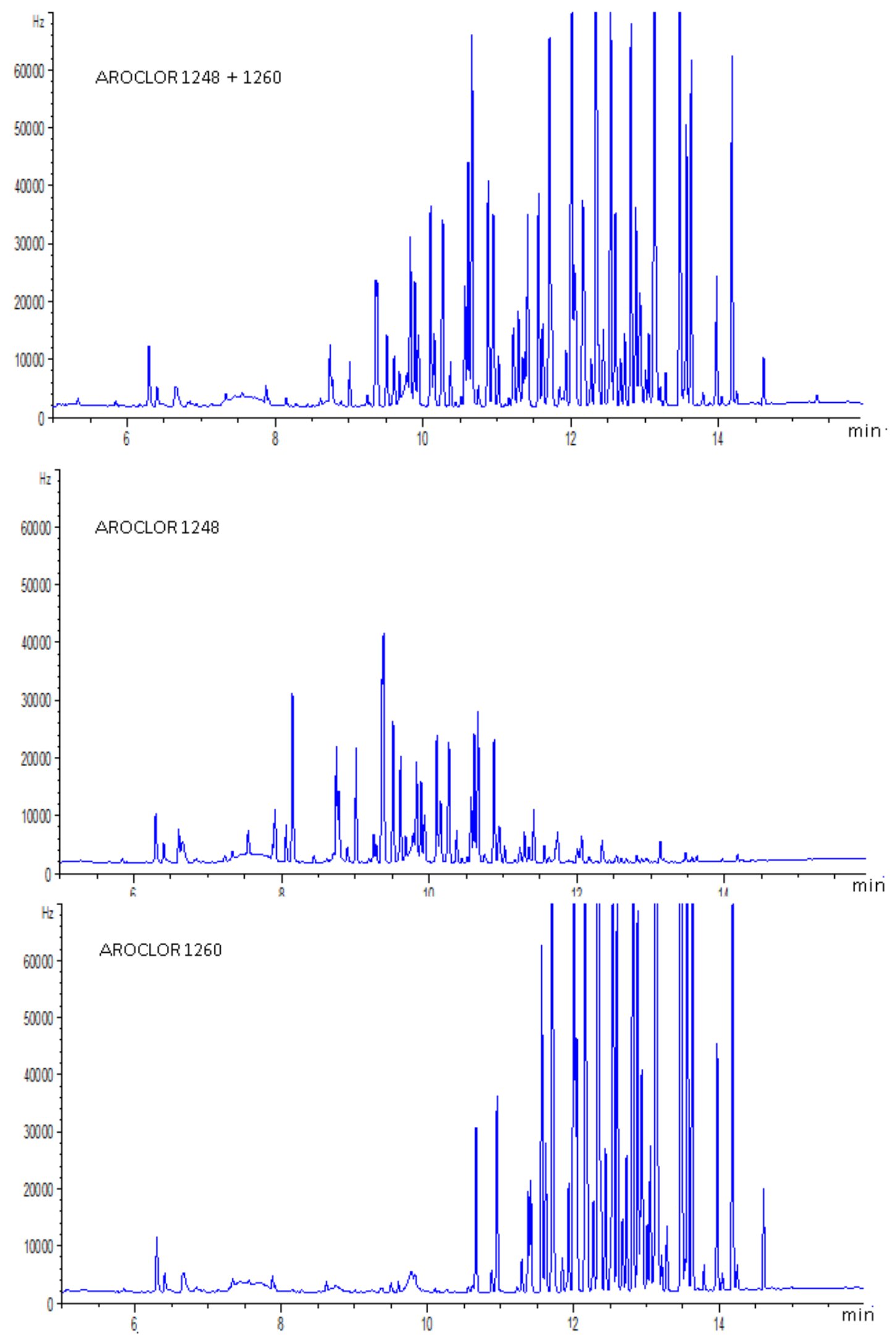

Figure 4 : GC Chromatograms of Aroclor 1248 and 1260 
Jeevanantham et al. /Journal of Tropical Forestry and Environment Vol. 9, No. 02 (2019), 120-131
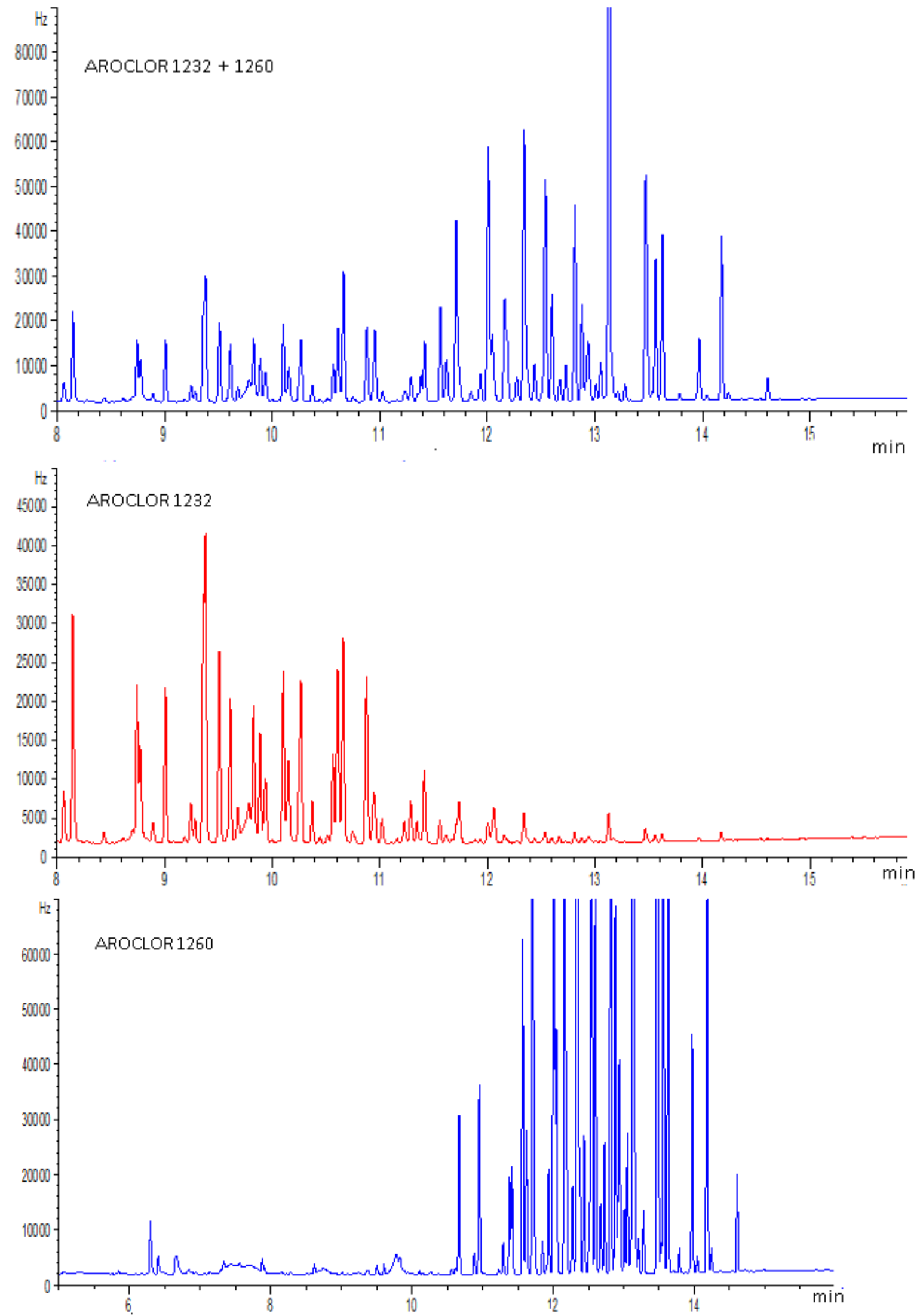

Figure 5: GC chromatograms of Aroclor 1232 and 1260 
By overlaying and screening peaks of retention times of $12.9 \mathrm{~min}, 13.2 \mathrm{~min}, 13.5 \mathrm{~min}, 13.8 \mathrm{~min}, 14.3 \mathrm{~min}$ were obtained. It was also assured that, the selected peaks utilized for the quantification of Aroclor 1260 were completely free from the interfering peaks present in other PCB congeners present in PCB 1248, 1016 and 1232 as clearly indicated in Figures 3, 4 and 5.

\subsection{Accuracy and Recovery}

Since a certified reference material was not available, accuracy of the method was evaluated using the recovery values. The recovery of the method covering the low, mid and high quantification levels of the analytical range were as $85 \%, 109 \%$, and $94 \%$ respectively.

\subsection{Precision}

The relative percentage standard deviation (\% RSD) for the fortified samples obtained were 5.1\%, 6.7\%, and $2.4 \%$ for quantification levels at $5 \mathrm{ppm}, 10 \mathrm{ppm}$, and $50 \mathrm{ppm}$ respectively.

\subsection{Limit of detection (LOD) and limit of quantification (LOQ)}

To the mean value obtained for the blank response fortified at the lowest detectable concentrations, the LODs and the LOQs evaluated for PCB by adding approximately 3 times and 5 times of the standard deviation of the response detected for the fortified blank at the lowest detectable concentrations were 2.5 ppm and 5 ppm respectively.

\subsection{Linearity and working range}

The method was found linear with a regression coefficient of 0.994 over the working range from $2.5 \mathrm{ppm}$ -100 ppm.

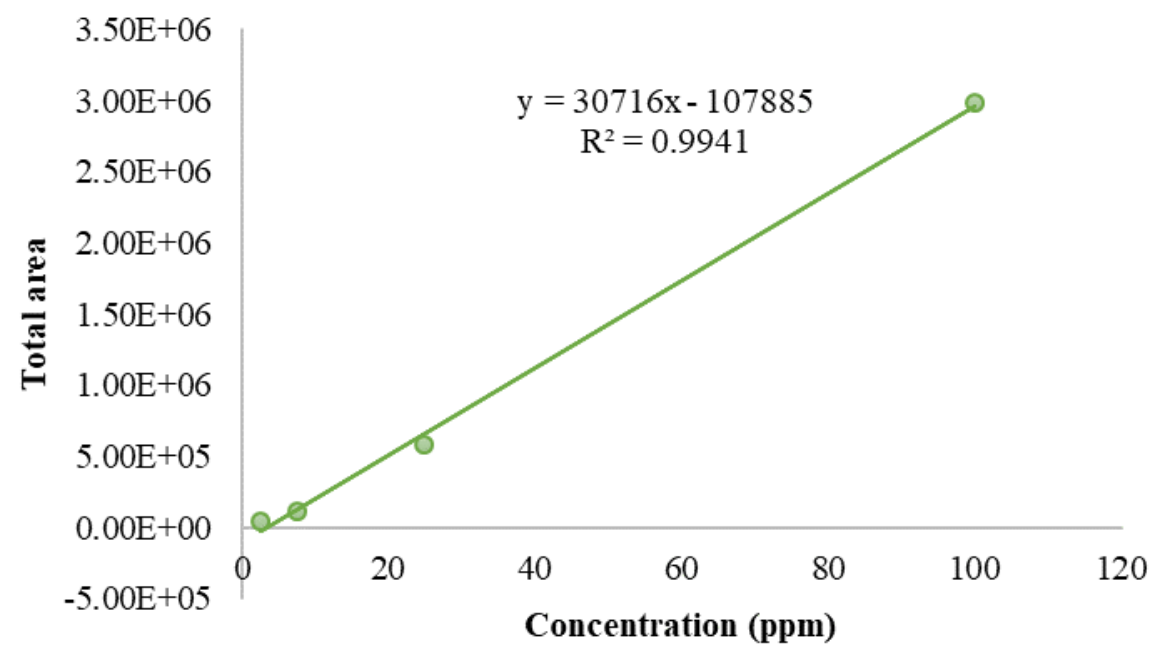

Figure 6: Calibration curve for total peak area of Aroclor 1260 vs Concentration

\section{Discussion}

In literature, PCB analysis has been carried out mainly using non polar solvents such as hexane, dichloromethane and toluene followed by SPE clean up (Na et al., 2008; Gordon, Szlta and Feeder, 1982). In comparison to the SPE cleanup, the method described here uses dispersive florisil cleanup which eliminates the requirement of use of SPE manifolds and is very cost effective(Ballschmiter and Zell, 1980). Further, the method presented is quick and fast enabling screening and quantification of Aroclor 1260 within 19 min which is lower than many of the methods described in literature for Aroclor analysis (Aries et al., 2004; Frame and Cochran, 1996) 
The method performance characteristics obtained for the analysis of PCBs in transformer oils were evaluated in comparison to the requirements mentioned in International method validation guidelines (AOAC,2012; EURACHEM, 2014).

Since unique chromatographic peaks were selected for the qualitative identification and quantitative analysis against Aroclor 1242 and Aroclor 1250, the selectivity of the analytical method was assured. Florisil clean up enabled removal of most of the complexities associated with the matrix. In addition, the interference arising from the matrix was further eliminated through the use of the matrix matched calibration conditions. The method was found accurate throughout the analytical range with mean recoveries found within the range from $80-110 \%$ which is the recommended acceptable recovery percentages for analytes which are present in ppm ranges (AOAC, 2012). The method was also found precise with mean relative standard deviations below 8\%. According to the AOAC Guidelines for Standard Method Performance Requirements, percentage relative standard deviation should be less than $11 \%$ (AOAC, 2012) for the analytes present in ppm levels. The linearity of the method was observed throughout the working range which extended from $2.5 \mathrm{ppm}-100 \mathrm{ppm}$. Further, with low LOD and LOQ values, the method enables sensitive detection of Aroclor which could be present in trace levels in transformer oils.

Prior to the injection of the samples fresh transformer oil (without Aroclor1260) was prepared in the same manner and injected to the GC-ECD to identify any solvent interaction between transformer oil and Iso Octane. Furthermore the fortified samples indicated the glassware and the reagents did not affect the extraction of Aroclor 1260 in the Iso Octane due to the recovery being between $80 \%$ - 100\%.

Therefore, all the method performance characteristics of the analytical method are in compliance with the requirements stipulated in international method validation guidelines.

\section{Conclusion}

The work described presents the method validation studies carried out on the analysis of Aroclor 1260 in transformer oils. The method is accurate, precise and sensitive and hence can be used for qualitative and quantitative analysis of Aroclor 1260 in transformer oil to study to the level of contamination of PCBs in transformer oils for the implementation of the national plan on phasing out of PCBs in Sri Lanka by 2025.

\section{Acknowledgments}

The authors gratefully acknowledge the financial assistance granted by the Industrial Technology Institute of Sri Lanka.

\section{References}

Andric, N. L. et al. 2006. 'Effect of a PCB-based transformer oil on testicular steroidogenesis and xenobiotic-metabolizing enzymes', Reproductive Toxicology, 22(1), pp. 102-110. doi: 10.1016/j.reprotox.2005.12.002.

Aries, E. et al. 2004. 'Development and validation of a method for analysis of "“ dioxin-like "” PCBs in environmental samples from the steel industry', 54, pp. 23-31. doi: 10.1016/S00456535(03)00762-8.

Ballschmiter, K. and Zell, M. 1980. 'Analysis of polychlorinated biphenyls (PCB) by glass capillary gas chromatography - Composition of technical aroclor- and Clophen-PCB mixtures', Fresenius' Zeitschrift für Analytische Chemie, 302(1), pp. 20-31. doi: 10.1007/BF00469758.

Bowman, J. et al. 2010. 'Preliminary Assessment of Polychlorinated Bipheynls (PCBs), Coengers, Aroclors, Dioxins, and Furans in the Sediment and Soil at the United States Department of Energy (DOE) Portsmouth Gaseous Diffusion Plant (PORTS), Piketon, Ohio', Preliminary PCB Assessment, p. 63. Available at: http://www.portsfuture.com/(Editor)_!78/PCB Assessment Report_final.pdf. 
Chris, L. (1991) 'Structural analogues’, Amino Acids, (January), p. 1991.

Correa, P. A. et al. 2010. 'The effects of individual PCB congeners on the soil bacterial community structure and the abundance of biphenyl dioxygenase genes', Environment International. Elsevier Ltd, 36(8), pp. 901-906. doi: 10.1016/j.envint.2009.07.015.

Erickson, M. D. and Kaley, R. G. 2011. 'Applications of polychlorinated biphenyls', Environmental Science and Pollution Research, 18(2), pp. 135-151. doi: 10.1007/s11356-010-0392-1.

Eurachem .2014. The fitness for purpose of analytical methods a laboratory guide to method validation and related topics. Available at: https://www.eurachem.org/index.php/publications/guides/mv (Accessed: 5 December 2018).

Fang, G. D. et al. 2012. 'Sulfate radical-based degradation of polychlorinated biphenyls: Effects of chloride ion and reaction kinetics', Journal of Hazardous Materials. Elsevier B.V., 227-228, pp. 394-401. doi: 10.1016/j.jhazmat.2012.05.074.

Frame, G. M. and Cochran, J. W. 1996. 'Complete PCB Congener Distributions for 17 Aroclor Mixtures Determined by 3 HRGC Systems Optimized for Comprehensive , Quantitative , CongenerSpecific Analysis', pp. 657-668.

Gordon, R. J., Szlta, J. and Feeder, E. J. 1982. 'Determination of Polychlorinated Biphenyls in Transformer Oils by Capillary Gas Chromatography', Analytical Chemistry, 54(3), pp. 478-481. doi: 10.1021/ac00240a028.

Grittini, C. et al. 1995. 'Rapid Dechlorination of Polychlorinated Biphenyls on the Surface of a Pd/Fe Bimetallic System', Environmental Science \& Technology. American Chemical Society, 29(11), pp. 2898-2900. doi: 10.1021/es00011a029.

Hoffman, D. J. et al. 1996. 'in Nestling American Kestrels ( Falco sparverius )', 0(0189), pp. 188-200.

IARC (International Agency for Research on Cancer) (2018) 'Agents Classified by the IARC Monographs, Volumes 1-121', IARC Monographs, (000050), pp. 1-25. doi: 10.1007/s13398014-0173-7.2.

Implementation, N. et al. 2004. under the Stockholm Convention on POPs for Sri Lanka.

Justice, E. and Lanka, S. 2006. 'Country Situation on Persistent Organic Pollutants ( POPs ) in India', 2(March).

Kamohara, K., Yagi, N. and Itokawa, Y. 1984. 'Mechanism of lipid peroxide formation in polychlorinated biphenyls (PCB) and dichlorodiphenyltrichloroethane (DDT)-poisoned rats', Environmental Research, 34(1), pp. 18-23. doi: 10.1016/0013-9351(84)90071-9.

Lang, V. 1992. 'Polychlorinated biphenyls in the environment', Journal of Chromatography A, 595(1-2), pp. 1-43. doi: 10.1016/0021-9673(92)85144-I.

Lohmann, R. and Dachs, J. 2019. 'Polychlorinated Biphenyls in the Global Ocean', World Seas: an Environmental Evaluation, 220, pp. 269-282. doi: 10.1016/b978-0-12-805052-1.00017-6.

Na, Y. et al. 2008. 'Chemosphere Determination of polychlorinated biphenyls in transformer oil using various adsorbents for solid phase extraction', 73. doi: 10.1016/j.chemosphere.2006.12.102.

ONU 2009. 'Stockholm Covention on Persistent Organic Pollutants (POPs)', Secretariat of the Stockholm Convention on Persistent Organic Pollutants, p. 56. Available at: http://www.wipo.int/edocs/lexdocs/treaties/en/unep-pop/trt_unep_pop_2.pdf. 
Jeevanantham et al. /Journal of Tropical Forestry and Environment Vol. 9, No. 02 (2019), 120-131

Reiter, E. V. et al. 2011. 'Uncertainty from sampling in measurements of aflatoxins in animal feedingstuffs: application of the Eurachem/CITAC guidelines', The Analyst. The Royal Society of Chemistry, 136(19), p. 4059. doi: 10.1039/c1an15124j.

Safe, S. 1985. 'Polychlorinated biphenyls (PCB s) and polybrominated biphenyls (PBB s): biochemistry, toxicology and mechanisms of action', 13(4).

Safe, S. H. 1994. 'Polychlorinated Biphenyls (PCBs):Environmental Impact, biochemical and Toxic Responses, and Implications for Risk Assessment', Critical Reviews in Roxicology, 24(2), pp. 87-149.

Schantz, S. L. 1996. 'Developmental neurotoxicity of PCBs in humans: What do we know and where do we go from here?', Neurotoxicology and Teratology, 18(3), pp. 217-227. doi: 10.1016/S08920362(96)90001-X.

Seegal, R. F. et al. 2011. 'Estimating the half-lives of PCB congeners in former capacitor workers measured over a 28-year interval', Journal of Exposure Science and Environmental Epidemiology. Nature Publishing Group, 21(3), pp. 234-246. doi: 10.1038/jes.2010.3.

Shin, S.K. et al. 2006. 'Levels of polychlorinated biphenyls (PCBs) in transformer oils from Korea', Journal of Hazardous Materials, 137, 1514-1522.

Stockholm Convention 2001. 'Persistentent organic polutants and the Stockholm Convention : A Resource Guide', Resource Futures International for the World Bank and CIDA, (September), pp. 1-24. Available at: http://worldbank.org/INTPOPS/214574-

1115813449181/20486510/PersistentOrganicPollutantsAResourceGuide2001.pdf. 